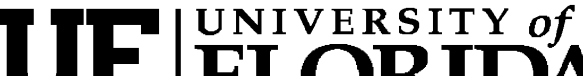 FLORIDA \\ IFAS Extension
}

\section{Collecting a Poultry Litter Sample for Analysis ${ }^{1}$}

George J. Hochmuth, Justin T. Jones ${ }^{2}$

Through research, tables have been developed that describe the average nutrient concentration of animal wastes. However, the actual nutrient concentration of manures may vary from one livestock operation to another. Factors that contribute to this variation include: composition of the feed ration, design of the waste management system, season of year, animal health, etc. Therefore, it is important that livestock wastes are sampled and analyzed to determine their nutrient concentrations before a sound, nutrient management plan can be designed, implemented, or maintained.

\section{Sampling Frequency}

Ideally, manure should be sampled before each field application is made. Although accurate, sampling at this frequency can be costly when using commercial laboratories for analysis, and can be somewhat time consuming. Even in the most consistent conditions, manures should be sampled at least twice per year, preferably in winter and late summer to capture seasonal variation in the manure. Management of the waste can be improved if a sample is taken about a month prior to field application and again during field application. The first sample will allow time for a testing lab to analyze the manure and provide results of the analysis. Sampling when the manure is field applied allows you to calculate what nutrients were actually applied. A historical record can further provide guidance to how often samples should be collected as long as consistent management of the operation is maintained.

\section{Collecting a Poultry Litter Sample}

Poultry litter generally has a moisture content of less than 30\%, and also includes a large percentage of bedding material. This material usually consists of sawdust, but can also include wood chips or wood shavings. Manure and bedding materials are removed together during the cleanout procedures of a poultry house. The wood fibers within the litter tend to become compacted over time, adding to the difficulty in collecting a representative sample. Following are guidelines for collecting solid manure samples:

\section{Manure Spreader}

Collecting a sample from the manure spreader is one of the preferred methods of collecting a poultry liter sample, because it represents what is being applied to the field. Collecting a sample from the

1. This document is HS938, one of a series of Department of Horticultural Sciences, Florida Cooperative Extension Service, Institute of Food and Agricultural Sciences, University of Florida. November 2003. Please visit the EDIS Web site at http://edis.ifas.ufl.edu.

2. George J. Hochmuth, professor and center director, University of Florida, Institute of Food and Agricultural Sciences, North Florida Research and Education Center, Justin T. Jones, coordinator, research programs and services, University of Florida, Institute of Food and Agricultural Sciences, North Florida Research and Education Center - Suwannee Valley, Gainesville FL 32611. Visit the EDIS website at http://edis.ifas.ufl.edu.

The Institute of Food and Agricultural Sciences (IFAS) is an Equal Opportunity Institution authorized to provide research, educational information and other services only to individuals and institutions that function with non-discrimination with respect to race, creed, color, religion, age, disability, sex, sexual orientation, marital status, national origin, political opinions or affiliations. U.S. Department of Agriculture, Cooperative Extension Service, University of Florida, IFAS, Florida A. \& M. University Cooperative Extension Program, and Boards of County Commissioners Cooperating. Larry Arrington, Dean 
spreader is also the most convenient method as compared to collecting a sample from a stack or house.

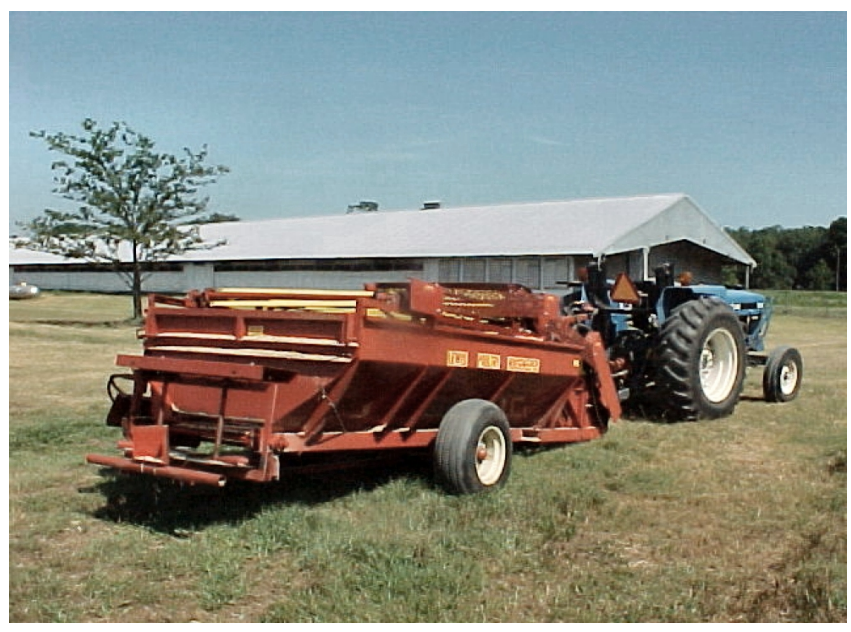

Figure 1. Manure Spreader

- Using a narrow bladed shovel, dig down into the manure in the spreader and withdraw at least 5 sub-samples at various depths. [It is also possible to use a thin-walled metal pipe that has a 3-inch diameter, is 4 to $5 \mathrm{ft}$ long, and sharpened on the bottom end. This pipe can be pressed or driven into the pile, using a wooden dowel or a broom handle to dislodge the sample from the pipe after it has been withdrawn.]

- Place all sub-samples into a clean plastic bucket, mix well, and place about a quart into a "ziploc"-type plastic bag.

- Label bag and deliver to testing lab as soon as possible.

\section{Stacks (including surface scrapings and mortality compost)}

Poultry litter will generally be stored on concrete under roofed structures. As such, they will be stored in stockpiles or stacks 5 to $6 \mathrm{ft}$ tall and may require special equipment to obtain a representative sample. In general, stacks are created in layers as houses are cleaned after a grow-out. This layering effect both changes the dynamics involved in collection, and overall effort required to collect a representative sample. Each layer in the stack will have slightly different properties within it, like moisture percentage, ammonia levels, etc. As equipment brings in additional layers, the stack becomes more compact and difficult in gathering a sample.

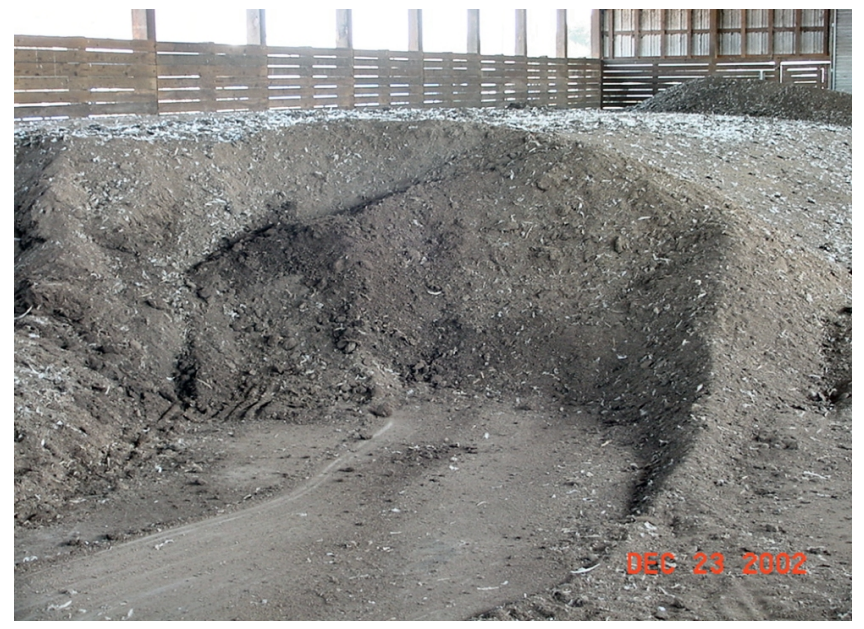

Figure 2. Poultry Stack

- Collection tools:

- Shovel. Using a narrow bladed shovel, brush away the exterior crust and dig down into the stack and withdraw from various depths. Each sub-sample should be collected at least 18 inches from the surface crust.

- Auger. Using a soil auger, a hole can be drilled more easily penetrating the compact layers of litter deep within the stack. The auger also facilitates collecting deep samples much more easily than the shovel. As with other samples, brush aside the loose surface litter and collect the sub-samples at least 18 inches below the litter surface.

- Pipe. It is also possible to use a thin-walled metal pipe that has a 3 -inch diameter, is 4 to $5 \mathrm{ft}$ long, and sharpened on the bottom end. This pipe can be pressed or driven into the pile, using a wooden dowel or a broom handle to dislodge the sample from the pipe after it has been withdrawn.

- Collect 10 to 12 sub-samples from all over the stack, extending as deeply as possible.

- Avoid feathers when collecting, if possible. 
- Place all sub-samples into a clean plastic bucket, mix well, and place about a quart into a "ziploc"-type plastic bag.

- Label bag (date, time, location) and deliver to testing lab as soon as possible.

\section{In-House Poultry Litter}

If a sample is to be collected while the manure is still in the poultry house, make special effort to collect a sample that is representative of conditions within the house. For example: if watering systems, feeders or cages take up $20 \%$ of the space within the house, then $20 \%$ of the sub-sample should represent these areas ( 2 out of 10, or 3 out of 15 sub-samples should be taken from these areas).

- Using a small bladed shovel, collect at least 10 sub-samples of the litter from the surface to the full depth of the accumulation.

- Place all sub-samples into a clean plastic bucket and mix all sub-samples well.

- Place about a quart of the litter in a "ziploc"-type plastic bag.

- Label bag (date, time, location) and deliver to testing lab as soon as possible.

- For layer operations, or other operations where cages are used, collect at least 10 sub-samples to the full depth of accumulation under the cages, following the directions outlined above.

\section{Preparing the Sample for Delivery to a Testing Lab}

The first step in preparing a sample for analysis involves completing all required forms as accurately as possible. This will begin primarily with the Sample Submission Form. Each lab analyzing livestock wastes will have their own list of required information needed to analyze the waste and create the analysis report. Provide as much information as is required by writing legibly and concisely.

It is also important to take special care of the sample once collected. All samples should be delivered to the lab as soon as possible after collection. If immediate delivery is not possible, refrigerate samples until delivery is possible. Samples that are stored more than 14 days before delivering to the lab should be frozen.

- Deliver or mail samples to the lab as soon as possible.

- [DO NOT USE GLASS OR METAL CONTAINERS to collect or ship the sample. Glass can break if miss-handled and certain metals can contaminate samples. Use only clean plastic bottles, buckets, and/or bags.]

- Double bag all solid samples in a "ziploc"-type plastic bag.

- Attach a completed sample submission form to the samples, making sure that labels on the samples match what is on the form. It is helpful to enclose sample submission forms (and payment, if applicable) in a separate "ziploc"-type plastic bag to protect it in case of condensation, etc.

- Consider the postal schedule before collecting a sample. Samples collected and mailed early in the week will stand less chance of sitting idle in the postal system over a weekend.

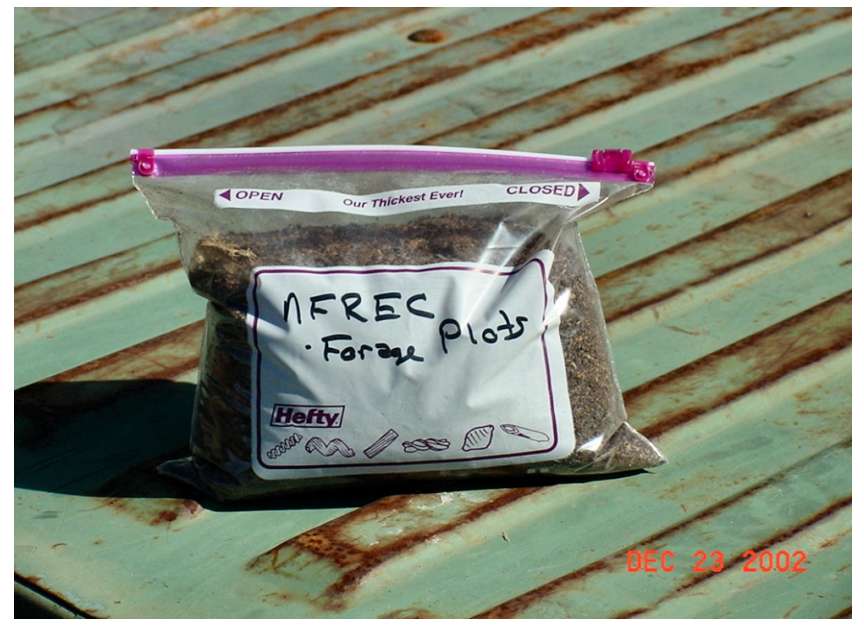

Figure 3. Poultry sample ready for delivery to lab.

\section{References}

Tyson, T. W. and C. C. Mitchell. 1998. Sampling animal waste for nutrient management: nitrate field testing. Circ. ANR-1102, Alabama Coop. Ext. Serv. 
Rasnake, M., D. Overhults and V. Case. 1997.

Livestock waste sampling and testing. Publication no.

ID-123, Kentucky Coop. Ext. Serv.

Barker, James. 1996. Livestock waste sampling, analysis and calculation of land application rates.

Publication no. EBAE 111-84, North Carolina Coop.

Ext. Serv.

Fulgagem, Charles D. 1993. Laboratory analysis of manure. Water Quality Initiative

Publication WQ0215, Dept. of Agric. Engineering, Univ. of Missouri-Columbia.

Vendre II, P. F., P. B. Bush and D. E. Kissel. 2001. Soil, manure and monitoring well testing in Georgia. Certified Nutrient Management Specialist Training Manual, Chapter 3. Univ. of Georgia Coop. Ext. Serv.

Lorimor, J. and W. Powers, Animal Science Dept., Iowa State Univ. Sutton, A., Animal Science, Purdue Univ. "Manure characteristics: manure management systems series." Publication no. MWPS-18 Section 1, Midwest Planning Service. 2000

Peters, J., editor. 2003. Recommended Methods of Manure Analysis (A3769). University of Wisconsin - Extension. http://www1.uwex.edu/ces/pubs/pdf/A3769.pdf 